\title{
Do mangue ao cabaçal: a modernização do passado na música nordestina
}

\section{Mangrove cabaçal to do: the modernization of the past in northeastern music}

\author{
Jane Meyre Silva Costa*
}

\begin{abstract}
Resumo: A proposta deste artigo é realizar uma discussão no campo da música, sobre o processo de hibridação cultural que se desenvolve no início dos anos 1990. Uma das primeiras expressões atuais na música contemporânea pode ser atribuída ao Movimento Manguebeat, que emergiu na década de 1990, no cenário da globalização cultural. Nesse contexto, começam a ser relativizadas as diferenças entre o tradicional e o moderno. Na cena cultural cearense, a proliferação de bandas com essa perspectiva culminou com a criação do Movimento Cabaçal nos anos 2000, sobre o qual realizamos um estudo empírico a partir de entrevistas semiestruturadas com os representantes das quatro bandas integrantes do Movimento Cabaçal.
\end{abstract}

Palavras-chave: Hibridação. Música. Cultura.

\begin{abstract}
This article purpose is to discuss, in the field of music, the process of cultural hybridization that develops in the early 90 s. One of the first up to date expressions in contemporary music can be attributed to Manguebeat Movement, which emerged in the $90 \mathrm{~s}$, in the setting of cultural globalization. In this context, the differences between traditional and modern start to be relativized. In Ceará cultural scene, the proliferation of bands with this approach led to the creation of the Cabaçal Movement in the 2000s, leading us to conduct an empirical study using semi-structured interviews with representatives of the four bands that compose the Cabaçal Movement.
\end{abstract}

Keywords: Hybridization. Music. Culture.

Recebido em: 12/03/2012. Aceito em: 11/01/2013.

\footnotetext{
* Mestre em Políticas Públicas e Sociedade pela Universidade Estadual do Ceará (UECE). Professora do curso de Serviço Social da UECE. Fortaleza, Ceará, Brasil. E-mail: janemsc@yahoo.com.br
} 


\section{Introdução}

Conhecer a movimentação artístico-musical dentro do cenário juvenil no Estado do Ceará, bem como a relação tradição-modernidade que Ihe é intrínseca, foi de grande valia desde a graduação no curso de Serviço Social.

A pesquisa, iniciada em 2003, cresceu junto ao próprio movimento aqui estudado - que, graças à mídia e à panfletagem espalhada pelas ruas de muitos bairros em Fortaleza, está em plena atividade desde então. Os shows eram constantes e as bandas muitas vezes se apresentavam juntas ou em duplas, sempre trazendo o nome do Movimento Cabaçal como temática central. Mesmo dialogando com a cultura local, são vários os estilos que compõem as bandas Jumentaparida, mais próxima ao Hardcore; DZefinha e Dr. Raiz, mais teatral, e a SoulZé, de estilo soul.

A pesquisa realizada foi resultado de inúmeras participações nos eventos que mobilizaram a cidade. Além do contato pessoal com os vocalistas, anotações referentes a performances, indumentárias e letras das músicas serviram como ferramenta de estudo.

O propósito deste trabalho, tendo em vista o contato direto com os integrantes do Movimento, é discutir algumas categorias fundamentais que levaram à fusão das várias culturas dentro e fora do Nordeste e sua relação com a mundialização cultural. $O$ interesse em pesquisar o envolvimento da juventude em movimentos artístico-culturais que se propõem a um diálogo com a cultura popular nordestina emergiu a partir da identificação de sua presença no cenário contemporâneo das cidades, sobretudo após a visibilidade adquirida pelo Manguebeat na década de 1990, em Recife. Foi a partir dessa década que uma série de bandas identificadas com essa proposta começou a fazer sucesso entre o público jovem nas principais cidades do Nordeste e do Brasil como um todo.

\section{Os anos 1990 e a globalização: diálogo entre o "local" e o "global"}

A década de 1990 teve seu início marcado pela era da virtualização, da informatização e da internet. Esses termos passaram a ser utilizados como palavras-chave para expressar a expansão global das culturas urbanas, ${ }^{1}$ o que, de um lado, é registrado como aumento da "sociocultura" ("cultura para todos"), e, de outro, tem provocado reações de caráter cultural, na forma de uma volta às obras clássicas e à estética tradicional.

Aglobalização é tida como uma espécie de "unificação do mundo", onde as fronteiras entre os países supostamente deixariam de existir diante da mundialização da economia de mercado, da crise dos chamados Estados nacionais e do fluxo de informações, inovações tecnológicas e capitais em escala global.

A cultura se apresenta por muitos como "homogeneizada" em relação à difusão de valores, comportamentos, estilos de vida e padrões de consumo urbanos pautados pela lógica do mercado e da mídia. Por outro lado, esse mesmo processo incorpora as chamadas culturas regionais, que se transformam por meio do contato com o mercado, a mídia e a cultura urbana, pois, com a evolução cada vez maior das cidades, estas se tornam palco das principais cenas culturais na contemporaneidade, colocando em cena, no mesmo patamar, o culto e o popular, o tradicional e o moderno.

Assim, a cidade passa a ser palco de uma mudança substancial nas relações culturais. "A cultura urbana é reestruturada ao ceder o protagonismo do espaço público às tecnologias eletrônicas. Como quase tudo na cidade 'acontece' porque a mídia o diz e como parece que ocorre com a mídia quer, acentua-se a midiatização social" (CANCLINI, 2000, p. 290).

O sentido da cidade se restabelece, e esta passa a ser não apenas o espaço onde se vive, transformando-se em "expressão amplificada de poderes locais” (CANCLINI, 2000, p. 288).

A importância da mídia e dos veículos de comunicação torna-se cada vez maior devido

\footnotetext{
1 "Por conta das transformações ocorridas nos centros urbanos durante a passagem do século $X X$, a cidade transformou-se no ambiente onde se revelam tendências estéticas que dela obtêm seus fundamentos. Nesse "laboratório social", onde a diferença e a pluralidade assumem lugar de destaque, a confluência de diversas culturas tem criado várias movimentações, tendo a urbe como principal protagonista. Esta, aliada aos novos meios de comunicação da modernidade com suas doses de publicidade, forma novas experiências artísticas." (Monografia Manguebeat. A maravilha mutante: batuque, sampler e pop na música pernambucana dos anos 90,2002$)$.
} 
à velocidade informacional, que irá recombinar os espaços sociais, e o excesso de informação poderá ser o lócus de ressignificações culturais. A dinâmica presente na cultura urbana é interdependente em relação aos fluxos comunicacionais presentes na cultura midiática. Dessa forma, diferentes modos de apropriação do tecido urbano formam diferentes produções de sentido, e a cidade se edifica sob uma perspectiva plural e heterogênea com a formação de uma nova linguagem cultural. Segundo Canclini (1998, p. 301), "As lutas semânticas para neutralizar, perturbar a mensagem dos outros ou mudar seu significado, e subordinar os demais à própria lógica, são encenações dos conflitos entre as forças sociais: entre o mercado, a história, o Estado, a publicidade e a luta popular para sobreviver".

Nessa nova construção societária, aliada ao mercado consumidor que o circunda, encontraremos uma trama visual de figuras de valor tradicionais, aliadas a objetos contemporâneos, pois "No movimento da cidade, os interesses mercantis cruzam-se com os históricos, estéticos e comunicacionais" (CANCLINI, 2000, p. 301). Portanto, a cidade irá abranger elementos de cunho tradicional e moderno no mesmo patamar, havendo uma reorganização entre os grupos e sistemas simbólicos, e realizando-se uma mistura entre culturas tradicionais e artes modernas.

As vasilhas, as máscaras e os tecidos encontram-se agora sob o nome de "artesanato" nos mercados urbanos. Se queremos comprar os mais bem feitos, já não vamos para as serras ou para as selvas onde vivem os índios que os produzem, porque as peças de diversos grupos étnicos se misturam nas lojas das cidades. (CANCLINI, 2000, p. 303).

Novos espaços "societais" são construídos através dessa conexão entre o tradicional e o contemporâneo, e, com isso, movimentos vão surgindo em busca dessa interação entre dois mundos.

Essa dilatação do eu para além da pele tradicional, alongando desmedidamente suas fronteiras de pele demasiado estreitas, esse reconhecimento do eu, mesmo ao longo dos fluxos comunicativos (não mais naturais) tecnovirtuais, constroem o engarrafamento de uma mutação entre o sensível e os sensores. (CANEVACCI, 1996, p. 70).
Canclini (2000) descreve a apropriação cultural através dos processos de territorialização e desterritorialização. A tensão entre as perdas das referências em relação aos aspectos tradicionais e a configuração de encadeamento cultural gera uma gama de possibilidades no âmbito da articulação entre a urbe e o processo de globalização, originando uma nova configuração cultural.

$\mathrm{O}$ autor delineia a linguagem das manifestações híbridas que nascem do cruzamento entre o culto e o popular. A fim de conter as formas dispersas da modernidade, investiga o fenômeno da cultura urbana, principal causa da intensificação da heterogeneidade cultural. É na cidade - portanto, na realidade urbana - que se processa uma constante interação do elemento local com redes nacionais e transnacionais de comunicação.

A Pós-modernidade não representaria uma substituição do mundo moderno, mas uma maneira de problematizar os vínculos equivocados que este armou com as tradições que, para constituir-se, quis excluir ou superar. Estabelece, pois, um diálogo entre a cultura de seu tempo e a pluralidade de informações obtidas não somente pela arte como também por intermédio da Economia, da História, da Filosofia etc.

Ao contrário dos ímpetos criativos dos modernistas, o pós-moderno não se traduz como uma produção de negação, mas suas experiências são apreendidas como um espaço de negociação, transformando a arte em um texto formado de múltiplos elementos.

De fato, atualmente a maioria das obras culturais que não contribuam para o crescimento do mercado cada vez mais pode ser eliminada, categorizada como "supérflua". A obra cultural que não seja convertível em mercadoria tende a ser descartada por seus criadores antes de sua exibição ou mesmo de sua execução, sendo geralmente os criadores de cultura os primeiros que olham os receptores de cultura como consumidores inseridos no mercado.

Segundo Canclini (2003), a globalização será um dos meios mais utilizados pela cultura para expansão de sua arte na década de 1990. Entretanto,

A Globalização acirra a concorrência internacional e desestrutura a produção 
cultural endógena, favorece a expansão das indústrias culturais com capacidade de homogeneizar e ao mesmo tempo contemplar de forma articulada as diversidades setoriais e regionais. (CANCLINI, 2003, p. 22).

Assim, existe uma espécie de contradição, onde o movimento cultural, ao mesmo tempo que critica esse processo global, precisa dele para sua expansão.

O desenvolvimento dos processos globais e a tendência à "homogeneização" cultural conduzem a uma relativização de alguns conceitos, como a existência do "local" (ou do "regional") e do "universal". No entanto, estudos sobre localismo começam a se apresentar novamente em contraposição a esta era global. A "perda" das tradições e da cultura local devido à "avalanche" de informações fez com que determinados conceitos tradicionais voltassem à cena cultural.

Com o início da era global, tanto os defensores do tradicionalismo como os ditos modernizadores passaram a ser questionados, pois quiseram construir objetos puros. Os tradicionalistas desejavam a construção de culturas nacionais e populares ditas por eles como "autênticas", procurando preservá-las da industrialização, da massificação urbana e das influências estrangeiras. Já os modernizadores quiseram conceber a arte em seu sentido pleno, sem fronteiras territoriais, por meio da inovação.

Essa visão maniqueísta que divide os conceitos de cultura tradicional e moderna é combatida por Canclini (2000), que teoriza sobre a importância do hibridismo nas culturas contemporâneas. O autor afirma ainda que os aspectos culturais globais não perdem sua relação com o local, devido à complexidade do mundo em que vivemos, caracterizado pela multiculturalidade ou "hibridização" cultural: "hoje todas as culturas são de fronteira. Todas as artes se desenvolvem em relação com outras artes. Assim, as culturas perdem a relação exclusiva com seu território, mas ganham em comunicação e conhecimento" (CANCLINI, 2000, p. 348).

A visão de que a modernização acabaria com as crenças e os bens tradicionais, e que os mitos seriam substituídos pelo conhecimento científico ou o artesanato pela expansão das indústrias, como salientam os defensores do tradicionalismo, é equivocada. A hibridação cultural nasce justamente para conectar esses dois valores. $O$ desenvolvimento moderno não suprime as culturas populares tradicionais, mas estas se transformam e adquirem novos significados a partir das relações estabelecidas com o mercado, a mídia e o consumo. Canclini menciona, por exemplo, a emergência de uma indústria cultural regional, que se expande em função de fatores como:

A impossibilidade de incorporar toda a população à produção industrial urbana. A necessidade de o mercado incluir as estruturas e os bens simbólicos tradicionais nos circuito massivos de comunicação, para atingir mesmo as camadas populares menos integrados à modernidade. $\mathrm{O}$ interesse dos sistemas políticos em levar em conta o folclore a fim de fortalecer sua hegemonia e sua legitimidade. A continuidade na produção cultural dos atores popular. (CANCLINI, 2000, p. 215).

O autor descreve ainda a necessidade desse tipo de indústria cultural, que se ocupa, também, dos consumidores "resistentes" ao consumo uniforme, diversificando a produção de meios para se adequar a todos os estilos e anseios. Com isso, o tradicional/regional/popular é transformado na interação com o moderno/ urbano/globalizado, o que demonstra que a "mercadoria cultural" também tem de se adequar aos consumidores em busca de novos valores culturais.

Os encontros culturais envolvem nações, etnias, classes sociais, aspectos culturais tradicionais e contemporâneos, realçando o hibridismo como uma das características mais marcantes dos tempos atuais. Hoje, é comum encontrar, nas feiras das metrópoles, produtos artesanais expostos ao lado das novidades eletrônicas, reordenando as fronteiras do que antes era reconhecido como "espaços diferenciados".

Neste cenário multicultural e complexo, presenciamos a emergência de movimentos artísticos-culturais envolvendo jovens do meio urbano cujas estéticas dialogam com o regional-popular e o global. A discussão sobre esta década, no que se refere a sua importância para a compreensão das expressões artísticas da juventude cearense, será tema do próximo tópico. 


\section{As transformações da música nos anos 1990}

Ariza (2006) traça uma definição sobre quatro modalidades de músicas que ele considera mais importantes. Depois do samba, da Bossa Nova e da Tropicália, é a vez da denominada world music ou world beat, de amplitude internacional, o que acaba culminando em um hibridismo cultural sem fronteiras. São categorizações adotadas por especialistas do mercado fonográfico atual, consideradas segmentos da música popular brasileira, em todos os seus desdobramentos e fusões de ritmos.

A world music, pensada como algo além da identificação de um produto comercial, pode ser apreciada sob várias perspectivas. Uma delas seria o interesse "pós-fusão" pelas formas tradicionais em si mesmas, certa curiosidade em conhecer experimentações "puras" de origens tão inéditas, quanto diversas [...] Seria uma espécie de turismo através dos sons. [...] Já sob outro ângulo, trata-se da continuidade dos processos de misturas musicais, já não operados dentro do âmbito do jazz e sim do pop. (ARIZA, 2006, p. 293).

O autor explica que esse "novo" processo musical foi surgindo durante a década de 1990 em todo o mundo devido ao esgotamento do pop internacional e à necessidade do mercado fonográfico de se voltar para um público cada vez mais exigente.

Além desses motivos, o autor declara que esse movimento surgiu, também, devido à inquietude e a motivações particulares dos jovens músicos, os quais almejavam se "abrir" para novos estilos e experimentações, cansados do que estava exposto no mercado mundial. Ou seja, essa movimentação foi positiva tanto para o mercado fonográfico, ávido por experimentações novas, como para o público e para os músicos.

Apesar de o mercado investir em novas recriações, é importante salientar que a chamada world music surgiu não somente de uma necessidade econômica, mas também do processo de constante mutação cultural. Dentro dessa mistura de ritmos envolvendo culturas diferentes, é difícil conceber uma definição única, homogênea, para essa categoria musical. Está muito mais próxima de um gênero, com todas as suas nuances e desdobramentos.
Ariza (2006) destaca dois processos pelos quais passa a música brasileira hoje. O primeiro típico dos Estados Unidos, é o jazz fundido à música eletrônica; o segundo é o processo de miscigenação que envolve aspectos tradicionais e expressões contemporâneas.

$\mathrm{Na}$ visão do autor, esse fenômeno vem acontecendo devido ao processo de "mundialização", que se intensificou tanto na área econômica como na cultural.

O processo de globalização, então, movimenta-se em direção ao estabelecimento de um sistema econômico e cultural comum a diversas e dispersas realidades, desde diversos centros hegemônicos, dirigindo-se a certa universalização. Ele, por outro lado, também dá lugar a um movimento de contrapartida, que se origina nas localidades (denominado globalização no Japão), exaltando o "particular" e coexistindo, assim, dois processos de comunicação: um global e outro local, sem serem plenamente harmônicos. (ARIZA, 2006, p.73).

Essa cultura, que vem emergindo dentro de um processo histórico, não está ligada a nenhum contexto espaçotemporal. Surge aliada à intensa miscelânea de componentes trazidos pelos meios de comunicação global, influenciando, assim, as composições artísticas em geral.

Na música, um dos melhores exemplos dessa manifestação artística é o Manguebeat. Iniciado na década de 1990 por jovens da zona urbana de Recife, teve como proposta inicial fundir gêneros musicais. A ideia foi mesclar elementos da cultura nordestina, como maracatu, ciranda, coco-de-roda, embolada, caboclinho, com gêneros da música pop global, como rap, soul, funk, hip-hop, o rock alternativo e a nova música eletrônica. O movimento foi uma forte inspiração aos jovens músicos das gerações seguintes, entre eles, indubitavelmente, o próprio Cabaçal.

Fazer interagir o velho com o novo era o intento de Chico Science, que trabalhou a fusão de elementos tradicionais da música popular em meio a um contexto atual diverso e repleto de sons eletrônicos. Sua realidade era o mangue, a desigualdade social evidente na cidade de Recife, a História da região, entre outros ingredientes que, juntos, se fundiram em uma 
complexa agregação de batidas e sonoridades.

Invocando o espírito de luta, Chico Science utilizou como temática de suas músicas o mangue, algo bastante presente em sua realidade, fazendo alusão à sua fertilidade, diversidade e riqueza. Sua imagem símbolo era a antena parabólica enfiada na lama, com o objetivo de engendrar um "circuito energético" capaz de conectar as boas vibrações dos mangues com a rede mundial de circulação de caráter pop.

Paralelamente ao Manguebeat, outros atores dessa nova cena cultural entram em cena, vindos de várias vertentes, como as bandas Mundo Livre S/A, Mestre Ambrósio, Sheik Tosado, Jorge Cabeleira e o Dia Em Que seremos Todos Inúteis, dentre outras. O Movimento Cabaçal (DZefinha, Dr.Raiz, SoulZé, Jumentaparida) se considera herdeiro e contemporâneo dessa nova cena cultural no Ceará.

Segundo as análises da monografia intitulada A Maravilha Mutante: Batuque, sampler e pop na música pernambucana dos anos $90^{2}$, os movimentos culturais da juventude no cenário atual, a exemplo do Manguebeat, representam uma nova postura frente à cultura convencional, realizando uma "antropofagia cultural."

Nesse sentido, setenta anos após o Movimento Antropofágico, o Manguebeat é reinterpretado como uma expressão estética canibalesca como a idealizada por Oswald de Andrade, pois se caracteriza musicalmente pela fusão de ritmos, tendo o sincretismo entre o global e o local como marca de sua estética. O tambor tribal se juntou à guitarra e aos amplificadores norte-americanos, com o objetivo de universalizar os

\footnotetext{
${ }^{2}$ Disponível em:

$<$ <ttp://www.manguebit.org.br/teses/maravilhamutante.doc>.

${ }^{3}$ Termo nascido inicialmente com Oswald de Andrade, com seu Movimento Antropofágico, que significa em sua essência um gesto relacional próprio da cultura brasileira, onde as diversidades se apresentam inconciliáveis. A Antropofagia representará então a deglutição, sob a perspectiva oswaldiana e selvagem. A antropofagia preconiza uma espécie de transubstanciação na qual aquele que é o devorador se altera no devorado. Ao propor o canibal como sujeito transformador, social e coletivo, Oswald produz uma releitura não só da história do Brasil, mas também da própria tradição ocidental. A antropofagia não é uma fome selvagem ou simbólica de carne humana, e sim um apetite direcionado, sensível e delicado, retesado para a escolha das partes corporais mais saborosas, para digerir o outro de forma criativa e não uma ingurgitação indiferenciada ou indigesta: o prato principal é o outro. Disponível em: <http://www.globalcult.org.ve/doc/CandidaRelea. doc>.
}

ritmos regionais, e trazendo a proposta de criar uma nova cena para o mundo. Estabelece-se assim um diálogo com as manifestações artísticas que trouxeram à tona um Brasil cosmopolita que é comparado ao Modernismo Antropofágico e ao Tropicalismo.

A Tropicália foi um movimento ocorrido no final da década de 1960, que tinha como proposta a mistura do arcaísmo e do moderno na música popular brasileira, fundindo elementos da música com a modernidade da vida urbana e sua cultura de consumo. Segundo Brandão e Duarte (1990), suas alegorias e sua linguagem metafórica criavam um humor crítico (paródia), que tentava superar a priorização entre as posições estéticas defensoras da cultura engajada e da cultura de massa.

Para Canevacci (1996), o sincretismo é umas das expressões que caracteriza alguns processos de criação artístico-cultural contemporâneos, sobretudo quando se analisa a relação estabelecida por certos movimentos estéticos entre os elementos da cultura global e da regional. Segundo esse autor, o sincretismo pode ser associado ao caráter antropofágico das criações culturais, pois,

Para conhecer uma ideia, uma escola, um autor estrangeiro, é preciso comê-lo, por meio de um verdadeiro ato de deglutição. Todo ato criativo é antropofágico: primeiro deve-se famelicamente devorar alguém, para, em seguida, após uma sadia deglutição reflexiva, regenerá-lo como algo totalmente diferente. (CANEVACCI, 1996, p. 29).

Além dessa dimensão sincrética atribuída ao Manguebeat, nesse movimento há também uma crítica social, pois os jovens integrantes se propuseram a abordar em suas letras os problemas enfrentados pela população, bem como a possibilidade de sua resolução. O movimento elaborou manifestos de caráter social, que buscavam a reflexão sobre uma sociedade que perde progressivamente suas raízes culturais.

No entanto, a grande diferença do Manguebeat em relação aos movimentos regionalistas tradicionais está nas letras das músicas. Chico Science procurou se apropriar da temática do local e da informação global na composição de 
seus textos e de sua sonoridade. Essa característica se expressa, por exemplo, na música Monólogo ao pé do ouvido, umas das faixas do CD Da Lama ao Caos. "Modernizar o passado é uma evolução musical".

É sobretudo por meio da batida, do ritmo, da experimentação e das criações sonoras que - Manguebeat, em seu primeiro momento, irá valorizar a música popular da região - mas não apenas como forma de preservação da cultura e do folclore pernambucano.

Science desejava "antenar" características regionais de suas músicas com o mundo contemporâneo. Com isso, percebe-se a forte influência de outros movimentos regionais, como o Movimento Armorial ${ }^{4}$ (porém, a sua principal diferença com relação a esse movimento é a tentativa de universalizar os elementos regionais).

O Manguebeat não objetiva a busca pelo regionalismo/nacionalismo por si só e sim a valorização das cidades e suas particularidades. Como relata Chico Science em uma de suas entrevistas acerca dessa relação com o Movimento Armorial, "A tentação de colocar numa espécie de solução em formol as manifestações populares nunca fez parte dos nossos planos. Muito pelo contrário, a ideia era dar condições para que elas pudessem dialogar com o mundo contemporâneo". ${ }^{5}$

O sincretismo é utilizado como termo principal para a compreensão da transformação que se desenvolve nesse processo de globalização. Trata-se de um novo modo de "originar cultura", realizando uma mistura de costumes e valores.

Portanto, o Manguebeat pode ser compreendido como uma das expressões das culturas juvenis no cenário das cidades em ritmo globalizado. O diálogo com a cultura da cidade, mais especificamente com a periferia, é uma das

\footnotetext{
${ }^{4}$ Movimento lançado oficialmente no Recife no dia 18 de outubro de 1970, por Ariano Suassuna, com o objetivo de valorizar a cultura popular do Nordeste brasileiro, pretendendo realizar uma arte brasileira erudita a partir das raízes populares da cultura do país. Segundo Suassuna, sendo "armorial" o conjunto de insígnias, brasões, estandartes e bandeiras de um povo, a heráldica é uma arte muito mais popular que qualquer coisa. Desse modo, o nome adotado significou o desejo de ligação com essas raízes heráldicas culturais brasileiras. Disponível em: <http://www.pe.az. com.br_cultura>.

${ }^{5}$ Entrevista concedida por Chico Science ao jornalista Sérgio Moriconi, publicada na revista O Radical.
}

marcas típicas desse movimento, assim como o culto à colagem, às recriações, com as hibridações configurando uma estética essencialmente antropofágica - a qual, segundo Canevacci, pode ser traduzida no sincretismo cultural.

O sincretismo representa-se como um "espectro" que recusa as sínteses filosóficas, os dogmas religiosos, as primazias nacionais. $\mathrm{E}$ devora, mastiga, absorve e vomita os resíduos sociais e o trash reciclado das variadas mundo-culturas, um espectro "glocal". (CANEVACCI, 1996, p. 25).

O movimento Mangue representa, pois, uma maneira de refletir sobre o momento de virada de século. Ao mesmo tempo que busca a raiz como um de seus principais elementos constituintes, como a origem do maracatu, das histórias da colonização e dos holandeses de Pernambuco, visualiza a decadência econômica das cidades em tempos de globalização. Atransformação do Recife em uma cidade que figura no ranking das piores do planeta para se viver e uma concomitante concentração de riqueza e poder são algumas questões que o movimento passou a enfatizar após sua estruturação.

Esse movimento utilizou como base teórica intelectuais como Gilberto Freyre e Josué de Castro, ${ }^{6}$ que foram integrados às bases do movimento e à preocupação social e cultural nas letras de suas músicas.

O sociólogo pernambucano Josué de Castro procurou relacionar as imagens dos caranguejos, principais habitantes dos mangues, com a vida das milhares de pessoas que sobreviviam da exploração destes. Em sua obra Homens e caranguejos, ele descreve:

Seres humanos que se faziam irmãos de leite dos caranguejos. Que aprendiam a engatinhar e andar com caranguejos da lama e que depois de terem bebido na infância este leite de lama, de se terem enlambuzado com o caldo grosso da lama dos mangues e de se terem impregnado do seu cheiro de terra podre e de maresia, nunca mais se podiam libertar desta crosta de lama que os tornava tão pa-

\footnotetext{
${ }^{6}$ Sociólogo pernambucano, autor do livro Homens e caranguejos, seu único romance, no qual o autor compara o ciclo de vida do homem miserável ao do caranguejo, que se alimenta dos dejetos orgânicos do mangue. Foi citado na música de Chico Science Rios, Pontes e Overdrives, do CD Afrociberdelia.
} 
recidos com os caranguejos, seus irmãos, com as duras carapaças também enlambuzadas de lama. [...] Vi os caranguejos espumando de fome à beira da água, à espera que a correnteza lhes trouxesse um pouco de comida, um peixe morto, uma casca de fruta, um pedaço de bosta que eles arrastariam para o seco matando a sua fome. E vi, também, os homens sentando na balaustrada do velho cais a murmurarem monossílabos, com um talo de capim enfiado na boca, chupando o suco verde do capim e deixando escorrer pelo canto da boca uma saliva esverdeada que me parecia ter a mesma origem da espuma dos caranguejos: era a espuma da fome (2001, p. 16-7).

Em Homens e caranguejos, o mangue obtém uma imagem de fonte de sobrevivência e vida, como se pode perceber nesta passagem do livro, onde Josué de Castro compara o mangue ao ato sexual - consequentemente, o mangue tornava-se símbolo da fecundidade:

[...] os mangues consagram todo o seu tempo a fazer amor. A abandonar suas folhas ao beijo impetuoso da corrente. A esfregar seus galhos, uns nos outros, com infinita volúpia. A atolar suas grossas raízes, com gozo, na lama garanhona do fundo do rio. Chico afirmava ter mesmo escutado, certas noites, o bailado nupcial do mangue no fundo das águas, e o estalar de seus caules membrudos gozando na carne da lama viscosa. Era um trepidar violento de amor que terminava num orgasmo final, derramando as sementes do mangue na água da cheia, para fecundar as novas terras que surgiriam na certa no ventre das águas. (CASTRO, 2001, p. 155-6).

Por sua vez, os regionalistas enfatizaram os aspectos mais folclóricos e tradicionais da Região Nordeste para compor sua narrativa. A cristalização de uma identidade nordestina foi demarcada por intelectuais como o sociólogo pernambucano Gilberto Freyre. Com sua teoria da mestiçagem, Freyre constituiu uma forma de unir o étnico ao cultural, valorizando ritmos tradicionais. Em Sobrados e mucambos, o autor trabalhou estudos fundamentais para uma concepção mais aprofundada sobre as raízes e características do povo brasileiro.

A ideia da mestiçagem surge num momento (décadas de 1920 e 1930) em que o Brasil se "inventava" como nação. Era preciso unificar econômica e culturalmente o imenso território brasileiro. Gilberto Freyre trabalhou com a ideia de miscigenação, mistura de povos e culturas, e conseguiu modificar os estudos referentes ao povo brasileiro e suas tradições.

A partir dos anos 1930, toda produção brasileira que almejasse a modernidade, fosse no cinema, na literatura ou na música, teria de, no mínimo, dialogar com essa noção. Ora para dar um sabor local à influência estrangeira, ora para renovar o regional com a novidade que vem de fora. Foi assim com a Bossa Nova, foi assim com o Tropicalismo. E, nos anos 1990, foi o que ocorreu com o Manguebeat.

Várias manifestações culturais utilizaram o Nordeste como principal "pano de fundo" de suas histórias. Seu clima, seu povo e seu linguajar eram referidos como um "retorno" à cultura de origem, tentando pontuar as principais características e singularidades da região.

Segundo Tinhorão (2001), a origem de todo esse interesse do público urbano pela música nordestina remonta ao século XIX, com a introdução da música rural, de caráter folclórico. A primeira compositora profissional a transformar em sucesso da música popular brasileira a estilização da música rural (e consciente de um gênero de música rural) foi Chiquinha Gonzaga, em 1897. O público urbano foi atraído pela música nordestina. Isso foi motivado principalmente pelo exotismo e pelo pitoresco, por sua linguagem diferenciada, sua musicalidade e seus ritmos. Canções e modas de viola do Nordeste atraíram o público da classe média. Era uma nova maneira de fazer música, e atraía por advir de uma realidade diferente.

Existia também o interesse de estabelecer uma contraposição entre dois mundos: a dura realidade urbana, com seu desemprego, fome, miséria, contrastando com o idealizado bucolismo das populações do interior - certamente pobres, mas gozando da tranquilidade com que a beleza natural pode Ihe retribuir. Esse "novo mundo" atraía a população urbana, com o sossego tão almejado pela turbulência dos dias nas cidades. Inicia-se então a expansão da visão do nordestino como homem rude e forte que consegue suportar as adversidades climáticas. Suas histórias e seu modo de falar tornam-se temas importantes nas músicas relacionadas a essa região. 
Ao mesmo tempo que é idealizado, o sertanejo forte é mitificado como homem rude e sem estudo, mão de obra barata que constantemente migra para as grandes cidades em busca de melhores condições de vida. As temáticas sobre seca, religiosidade, saudade, são constantes nessas músicas que buscam "resgatar" as origens do povo nordestino.

\section{Os anos 2000 no Ceará: a fusão de ritmos do Movimento Cabaçal}

No início dos anos 2000, seguindo a mesma corrente do Movimento Manguebeat, que busca a realização de uma releitura da cultura popular nordestina por meio da mistura de ritmos musicais, surge, no Ceará, o Movimento Cabaçal. O movimento foi iniciado por quatro bandas principais, SoulZé, Jumentaparida, DonaZefinha e Dr.Raiz, originárias de Fortaleza, Itapipoca e Juazeiro do Norte.

Esta pesquisa representou parte de um estudo realizado em minha monografia de graduação e complementada na dissertação de mestrado, em 2007, a partir de estudos teóricos, análise de músicas e entrevistas com os componentes das quatro bandas inseridas no Movimento Cabaçal.

Esse movimento, contemporâneo do Manguebeat, utiliza em seu repertório, além de ritmos e instrumentos típicos da cultura pop rock (guitarras, baixos e baterias), instrumentos, ritmos e músicas do universo das bandas cabaçais (pífanos, zabumbas, alfaias, rabecas e triângulos). Segundo seus integrantes - jovens em sua maioria de classe média e universitários -, com performances teatrais e mistura de ritmos, - Movimento Cabaçal busca a expansão e a divulgação da cultura nordestina (e especificamente da cultura cearense).

O movimento se iniciou em 2001, encabeçado por jovens cearenses da zona urbana do Estado, tendo como proposta fundamental a valorização da cultura regional nordestina. Uma de suas características principais é a utilização de instrumentos e ritmos provenientes de bandas cabaçais, também chamadas de "bandas de couro", que representam o conjunto musical mais típico do interior cearense, especialmente na região do Cariri. Esse estilo originou-se no meio dos escravos africanos, mas se desenvolveu e adquiriu peculiaridades próprias entre o povo do Cariri. Há também uma influência indígena, devido ao uso de instrumentos como pífanos e pífaros.

As bandas chamavam-se DZefinha, SoulZé, Jumentaparida e Dr.Raiz. Sua proposta seria aliar seus estilos musicais característicos - o hardcore, o soul - ao baião, ao coco e ao teatro popular, além de utilizar instrumentos típicos de bandas cabaçais, como zabumba, pífaro, alfaias, triângulo, pandeiros.

Um elemento tradicional bastante citado pelos jovens - e que gerou a própria denominação do Movimento Cabaçal - é a banda Cabaçal dos Irmãos Aniceto. Essa banda representa a "tradição" oral perpetuada pelas diferentes gerações e é descendente direta dos índios Cariri. Tem uma relação muito estreita com os elementos da natureza, em virtude de sua própria origem indígena. Além dessa formação musical, apresentava-se com de movimentos performáticos, imitando animais em seus shows por todo o país. Faziam algumas participações no início de espetáculos de bandas do Movimento Cabaçal. ${ }^{7}$

A união dessas bandas originou um $C D$, produzido em abril de 2002, intitulado CABAÇOM, A Mostra de Música do Movimento Cabaçal, composto por quatro músicas de cada banda (Dzefinha, Jumentaparida, SoulZé e Dr Raiz). Esse CD deu início a uma série de eventos culturais.

\section{Compreendendo as bandas}

A banda Dr. Raiz, originária de Juazeiro do Norte, foi fundada em 1998. Tem como alvo principal a fusão de elementos do rock com os da chamada "cultura popular nordestina". A ideia do nome veio do próprio vocalista Júnior Boca, inspirada em um cordel de Patativa do Assaré em que há um personagem com essa denominação:

A gente estava procurando algo que tivesse a ver com raízes, e aí a gente lembrou do cordel do Patativa do Assaré, e da própria figura do Dr. Raiz. Trata-se de um personagem que vive nas feiras livres, vendendo ervas medicinais às pessoas. A gente achou legal, levou lá... e todo mundo aceitou. (JÚNIOR BOCA, DR. RAIZ).

\footnotetext{
${ }^{7}$ Disponível em: <http//www.revistaangulo.com.br>.
} 
Em 2006, a banda Dr Raiz lançou um CD intitulado Cariri.Ce.Brasil, trazendo uma seleção de dezessete músicas. Segundo eles, sua fonte de inspiração são as manifestações culturais populares, como os reisados, as lapinhas, os pastoris, o ritmos das bandas cabaçais, o forró pé-de-serra, o maracatu, o coco, o maneiro-pau, a embolada e a cantoria. Assim como a banda Dzefinha, o Dr.Raiz também utiliza performances teatrais em seus shows. Em uma das músicas, intitulada Caldeirão, o cantor Júnior Boca se veste de Beato José Lourenço ${ }^{8}$ e realiza uma pequena encenação no palco.

A Banda Dzefinha, originária de Itapipoca, apareceu no cenário cearense em 2001. Veio com a proposta de integrar música e teatro, remetendo aos espetáculos de rua que ocorrem na cidade. Em suas apresentações, interage com a plateia, com brincadeiras e "contação" de histórias e "causos" populares.

Os três irmãos - Orlângelo Leal, Paulo Orlando e Ângelo Marcio - que, no início da carreira, tinham uma companhia de teatro, migraram para a música. Levaram consigo a "performance" corporal adquirida no teatro, que se tornou o verdadeiro diferencial da banda. Era "o teatro na música".

A banda lançou no mercado o primeiro CD, intitulado Cantos e Causos. O álbum compõe-se de doze faixas e já está esgotado. Nesse primeiro $C D$, segundo os próprios integrantes, é frequente a presença de três elementos principais: o cômi$\mathrm{co}$, rítmico e a dança popular.

O segundo $C D$, intitulado Zefinha Vai à Feira, vem com uma proposta bastante diferente da anterior. Orlângelo Leal explica o objetivo desse segundo trabalho: "A feira que batiza o CD é exatamente uma metáfora para o mundo. Para aparecer em meio à turba provocada pela globa-

\footnotetext{
${ }^{8}$ Aos 20 anos de idade, chegava à cidade de Juazeiro o paraibano José Lourenço Gomes da Silva, em busca de orientação do Padre Cícero. Este recomendou que fizesse uma penitência durante algum tempo e que depois voltasse. Em seu retorno, disse que tinha uma missão. Mandou que se situasse no sítio Baixa Dantas, onde o padre mandaria os romeiros mais desvalidos, fugitivos de perseguições. $O$ beato tornou-se pessoa de grande confiança de Padre Cícero. Após vários problemas, Padre Cícero perde o sítio e loca José Lourenço e seus seguidores na fazenda Caldeirão. Em pouco tempo, torna-se fornecedora de mão de obra, além de fertilíssima propriedade. Após a morte de Padre Cícero, Caldeirão é atacado por oficiais da polícia, devido ao receio de que se expandisse. O local foi saqueado e incendiado (SOUZA, 1994).
}

lização, marcada pelo consumismo desenfreado, é preciso também entrar no jogo do mercado. Globalização é se ofertar para o mundo."9

A banda SoulZé, criada em 1997 em Fortaleza, tinha como característica a mistura de uma levada da música soul com elementos nordestinos, apresentando uma batida diferente das outras bandas do cenário. Em sua busca por sons diferentes, flertam também com o samba-funk e o drum'n'bass.

A última banda, Jumentaparida $\mathrm{A}$ banda, fundada em 1998, era reconhecida como sendo o Hardcore Regionalista, por ter uma preponderância mais intensa da cultura rock. A constante presença das guitarras e da bateria faz seu diferencial dentro do Movimento Cabaçal. Foi a única, entre as quatro aqui pesquisadas, que não deu continuidade a seu trabalho, desfazendo-se em 2005. A falta de apoio estatal foi o motivo gerador, segundo seus integrantes, do fim do grupo, que se sentiu desmotivado em seguir a carreira artística.

O artista Zôo, vocalista, explica o porquê da escolha do nome da Banda, de forte sonoridade - a idéia partiu de seu tio - como algo que estivesse fortemente ligado ao cotidiano do sertão:

O Jumento é o bicho doido do sertão, que canta as alegrias e as desgraças do Nordeste e sai por aí distribuindo coices nas coisas erradas. Esse nome foi inventado por um tio nosso, o tio Toim, (...) e ele veio se encaixar perfeitamente no tipo de som que a gente queria fazer. ${ }^{10}$

A banda Jumentaparida era uma das mais bem cotadas em termo de público . A juventude identificava-se muito com sua música, talvez por seu caráter mais próximo do rock. Conseguiu realizar um clipe na casa de show Hey How, na cidade de Fortaleza, e lançar um cd homônimo, em sua curta trajetória musical.

Em seu cd, único lançado pela banda, constam 14 músicas, cujas letras apresentam estrofes mais longas. Estão divididas, em sua

\footnotetext{
${ }^{9}$ Entrevista concedida pela banda a Amanda Queirós, no jornal O Povo de 14 de junho de 2007. O título da matéria é "O balaio (High Tech) da Zefinha".

10 Disponível em http// www. paginas.terra..com.br/informática/ animescity/entrevista9.htm.
} 
maioria, em três ou quatro. A melodia prima por um som em que predominam as guitarras, os baixos e as baterias.

Atualmente o Movimento Cabaçal já não está mais presente no cenário musical cearense. Nos shows, não há mais referência a ele e as bandas já não se encontram, seguindo uma trajetória solitária, apesar de existir um site particular da Soulzé e da produtora Caldeirão das Artes, que ainda faz menção às bandas Dzefinha e Dr.Raiz.

As bandas Jumentaparida e Soulzé não deram continuidade a seu trabalho, desfazendo-se em 2005. Segundo seus integrantes, a falta de apoio estatal foi o motivo para o fim do grupos, que se sentiram desmotivados em seguir a carreira artística.

\section{Considerações finais}

O Movimento Cabaçal se traduziu como uma manifestação cultural dos jovens cearenses, caracterizada por sincretismo e hibridismo cultural. Configura uma "nova" estética musical, que utiliza uma linguagem plural em suas músicas, realizando uma mistura de ritmos e uma recombinação entre pop rock urbano e cultura popular nordestina.

Em suas performances teatrais, suas letras, seus ritmos e suas músicas, esses jovens propuseram uma discussão do elemento regional. Não tratam a tradição cultural como algo morto ou algo que lamenta as perdas advindas da globalização cultural. Sua atualidade se revela exatamente em seu sincretismo:

No sincretismo exprime-se o fim da lamentação pela perda da origem, da identidade fixa, da memória restauradora, que angustia a maioria dos cientistas sociais, pratica-se a felicidade corsária e marronizada ${ }^{11}$ da mudança de conceitos, projetos, métodos, imagens, poesias, arquiteturas, etnias e aforismos. (CANEVACCI, 1996, p. 10).

Embora expressem essa contemporaneidade, a cultura popular tradicional permanece

\footnotetext{
${ }^{11}$ Para Canevacci, a "marronização" representa uma outra forma de sincretismo cultural, tendo como conceito principal a mistura de diferenças - neste caso, não só étnicas, mas também de estilos de vida, visões de mundo e sensibilidades estéticas (CANEVACCI, 1942, p. 28).
}

vinculada ao espaço onde vivem - o sertão e o Nordeste, que são referidos na maioria de suas músicas como lugares que remetem a um passado mítico e bucólico. A cidade, diferentemente do que ocorre no Manguebeat, não é muito comentada em suas músicas. Representa apenas o espaço buscado pelos retirantes à procura de melhores condições de vida.

De maneira geral, esse movimento pode significar a busca de uma identidade local em meio ao processo de globalização cultural - por meio do diálogo com a "cultura popular nordestina". Mas representa também a possibilidade de articular novos sentidos para a juventude urbana, gerando vínculos, estilos de vida, valores e comportamentos que estabelecem, no presente, um diálogo entre o tradicional e o contemporâneo, 0 passado e o futuro.

O Movimento Cabaçal já não figura no cenário musical cearense. Opiniões dos integrantes das bandas divergem no que diz respeito à sobrevivência do movimento. Alguns acreditam que a história e a inspiração servirão de alicerce para grupos ou manifestações que ainda poderão ocorrer no Estado. Para outros, não existe mais um trabalho solidificado, uma vez que a alternativa foi partir para carreiras individuais, o que não comunga com o espírito do Cabaçal.

Alguns integrantes afirmam que havia grande interesse em continuar, mas que não tiveram incentivo e não puderam sustentar tamanho investimento. Cessaram as reuniões onde se debatia, entre outros assuntos, a própria questão da identificação dentro do movimento.

Nos relatos e depoimentos que serviram para articular este artigo, transparece a necessidade de sensibilizar a classe artística cearense para que sejam buscadas políticas de incentivo para fomentar criações e movimentos novos.

Partindo do pressuposto de que o Movimento Cabaçal representa uma forma organizada de manifestação social, por se postar a favor da valorização da cultura cearense, percebemos que há um interesse na discussão acerca da valorização de uma música autoral e de qualidade. Os depoimentos colhidos apontam para o fato de que essa questão vem sendo deixada de lado, esquecida em meio às resoluções e debates políticos que vem ocorrendo no Ceará. 


\section{Referências}

ALBUQUERQUE JÚNIOR, D. M. A invenção do Nordeste e outras artes. São Paulo: Cortez, 2001.

ARIZA, A. Eletronic Samba: a música brasileira no contexto das tendências internacionais. São Paulo: Annablume / Fapesp, 2006.

CANCLINI, N. G. Culturas híbridas: estratégias para entrar e sair da modernidade. Trad. Heloisa Pezza Cintrão e Ana Regina Lessa. São Paulo: Edusp, 2000.

Iluminus, 2003.

Globalização imaginada. São Paulo:

Culturas populares no capitalismo. Trad. Cláudio Novaes Pinto Coelho. São Paulo: Brasiliense, 1983.

CANEVACCI, M. Sincretismos: uma exploração das hibridações culturais. Trad. Roberta Barni. São Paulo: Studio Nobel, 1996.

CASTRO, J. Homens e caranguejos. Rio de Janeiro: Civilização Brasileira, 2001.

COSTA, J. M. S. Movimentos artístico-culturais no Ceará: uma interpretação do Movimento Cabaçal. Fortaleza: Monografia de Graduação do Curso de Serviço Social, 2004.

MONOGRAFIA MANGUEBEAT. A maravilha mutante: batuque, sampler e pop na música pernambucana dos anos 90. Pernambuco: UFPE, 2002.

PRIGGE, W. Metropolização. In.: PALLAMIN, V. M.; LUDEMANN, M. Cidade e Cultura: esfera pública e transformação urbana. São Paulo: Estação Liberdade. 2002.

TINHORÃO, J. R. Pequena história da música popular brasileira. Petrópolis: Vozes, 1975.

2001.

Cultura popular. São Paulo: Editora 34, 